\title{
EXTRACELLULAR VESICLES IN JOINT INFLAMMATION
}

Andrew D. Foers, Lesley Cheng, Andrew F. Hill, lan P. Wicks, Ken C. Pang

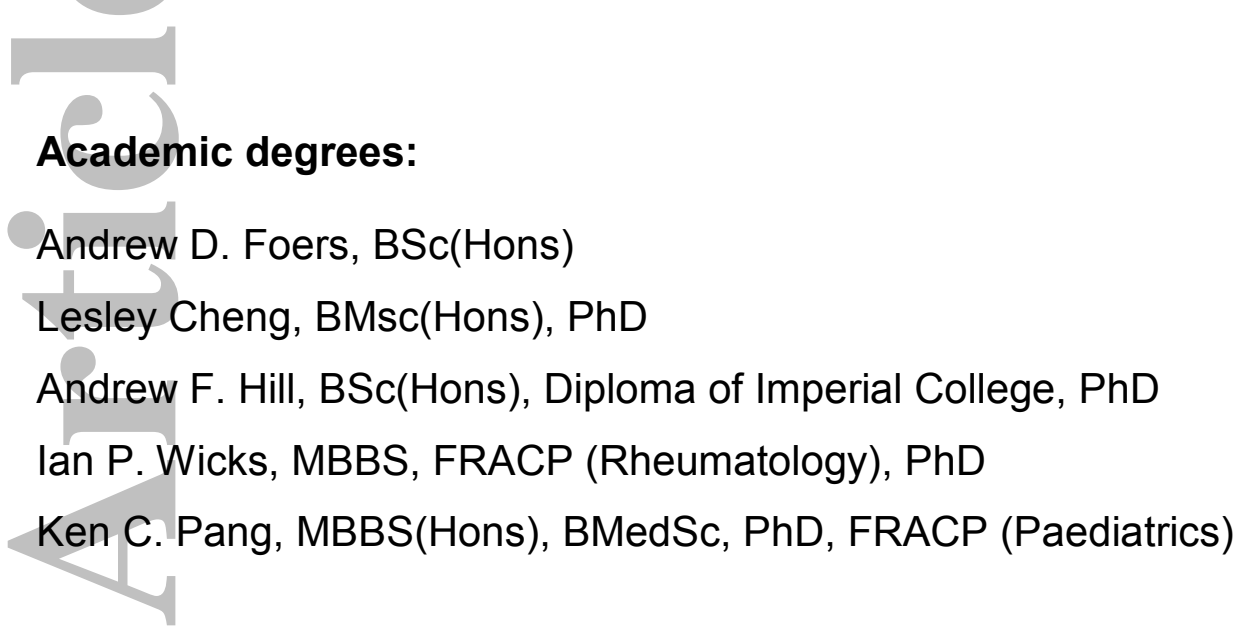

Correspondence should be addressed to:

Ken C. Pang lan P. Wicks

ken.pang@mcri.edu.au wicks@wehi.edu.au

Murdoch Childrens Research Institute, The Walter \& Eliza Hall Institute,

Parkville, VIC, AUS, 3052 Parkville, VIC, AUS, 3052

Phone: +6139345 5986

Phone: +619345 2466

Fax: +61393481391

Fax: +61393470852

\section{Financial disclosures and/or conflicts of interest:}

None declared.

This is the author manuscript accepted for publication and has undergone full peer review but has not been through the copyediting, typesetting, pagination and proofreading process, which may lead to differences between this version and the Version record. Please cite this article as doi:10.1002/ art.40076. 


\section{Introduction}

The pathological mechanisms underlying the development and maintenance of rheumatoid arthritis (RA) are incompletely understood, but broadly involve persistent joint inflammation that can lead to irreversible joint damage. In recent years, extracellular vesicles (EVs) have attracted increasing attention for potential roles in inflammation, including in inflammatory arthritis (1).

EVs are released from cells and are found in all types of bodily fluids. They are typically classified as exosomes, microvesicles or apoptotic bodies, according to the mode of biogenesis (Fig. 1). Exosomes and microvesicles are continually released from cells, whereas apoptotic bodies are released only as cells undergo apoptosis. The majority of research investigating EVs has been on exosomes and microvesicles and these will be the focus of this review. Having said that, EV nomenclature tends to be inconsistent within the literature, since it is technically difficult to isolate specific classes of EV, leading to methodological variability and a lack of consensus on not only optimal isolation techniques, but also what types of EVs are enriched (2). To ensure consistency within this review, we have therefore reviewed the isolation techniques within each study and adopted a consistent nomenclature. If a technique does not convincingly enrich for a particular class of EV, the general term EV is used.

EVs contain a heterogeneous collection of proteins, RNAs and lipids, which reflect the state of the particular cells from which EVs are derived. Interactions between EVs and other cells can occur in several ways (Fig. 2), enabling the molecular cargo of an EV to exert functional effects on recipient cells. It is clear that EVs can deliver molecules which drive disease. For example, EVs have been implicated in neurodegenerative disease through traffic of infectious, prionlike proteins (reviewed in (3)), and in cancer through the transfer of oncoproteins to promote metastasis (4). EVs can also functionally impact recipient cells though the transfer of RNAs, such as micro RNAs (miRNAs), which can influence expression of target genes, including those involved in inflammatory processes $(5,6)$. 
In the context of inflammation, EVs have been shown to exert both pro- and antiinflammatory effects. For example, exosomes from heat-stressed hepatocytes potently stimulate TNF- $\alpha$ expression in recipient macrophages via exosomeassociated HSP70 (7). Similarly, EVs from neuronal stem/precursor cells exposed to Th1 cytokines can activate STAT1 signalling via the delivery of EVbound IFN- $\gamma$ to its cognate receptor on recipient cells (8). Moreover, exosomes purified from human amniotic fluid or malignant ascites fluid can promote STAT3 and NFKB signalling in recipient monocytes, through activation of the Toll-like receptors, TLR2 and TLR4, leading to the release of cytokines such as TNF- $\underline{\alpha} a$, IL-1 $\beta$ and IL-6 (9). Similarly, exosomes derived from tumour cells contain specific miRNAs that act as agonists for endosomal Toll-like receptors in recipient immune cells (10). In contrast, some EVs have anti-inflammatory effects. SOCS family proteins are key suppressors of inflammation through inhibition of JAK-STAT signalling (11). Exosomes and microvesicles isolated from alveolar macrophages contain SOCS1 and SOCS3 respectively, both of which can attenuate STAT signalling (12). EVs derived from malignant ascites fluid can promote CD25 and FOXP3 expression in recipient T cells, leading to the expansion of immunosuppressive, regulatory cells that release inhibitory cytokines and increase resistance to apoptosis (13).

Separate to biological effects, EVs are also proving to be an important source of novel biomarkers, as the molecular cargo of EVs provides information about the cell of origin. Released EVs can be isolated from readily accessible fluids such as blood and urine. Together, these properties make EVs well suited as sources of biomarkers, as elegantly demonstrated by the finding of cancer-specific mRNA in serum microvesicles isolated from patients with glioblastoma (14). More recently, serum exosomes containing glypican-1 were found to distinguish between patients with pancreatic cancer, those with benign pancreatic disease and healthy controls with absolute sensitivity and specificity. Interestingly, the presence of glypican-1 in circulating exosomes preceded the MRI-detectable appearance of lesions in a mouse model of pancreatic cancer, prompting hope that exosomal glypican-1 might form the basis for an early diagnostic test (15). 
Indeed, there is now optimism regarding the use of exosomes for "liquid biopsies" in the oncology field, and the first exosome-based diagnostic test was recently brought to market. Exosomal biomarkers may also be useful outside of oncology $y_{2 ;}$ Cheng et al. recently showed that serum EV miRNAs distinguished patients with Alzheimer's disease from healthy controls, with high sensitivity and specificity. Moreover, this miRNA signature also showed promise in identifying apparently healthy subjects who developed Alzheimer's disease at a later stage (16).

Therapeutically, exosomes are being investigated for drug delivery, taking advantage of a natural role in transporting biological cargo between cells within the body. For example, siRNA based therapies have undergone clinical trials for a broad range of human diseases, but delivery has proven challenging for a variety of reasons, including extracellular RNases that rapidly degrade RNA and difficulty with specific targeting to the desired tissue or cell type. In this regard, EVs not only offer protection from RNases via a lipid membrane, but can also be modified to express surface proteins that allow targeting. As an example, exosomes have been loaded with siRNAs against BACE1, a therapeutic target in Alzheimer's disease, and then successfully targeted to neurons after being engineered to express the neuron-specific peptide RVG. Intravenous injection of these exosomes into mice successfully knocked down BACE1 expression within the brain (17). Similarly, another group used EVs displaying a peptide sequence that acts as an EGFR ligand to specifically target EGFR expressing breast cancer cells, with inhibition of tumour development in mice via delivery of a synthetic small RNA cargo (18). Finally, it is worth noting that the ability of EVs to deliver a defined molecular cargo to specific sites is analogous to liposomebased pharmaceuticals. Liposomes are small vesicles generated from synthetic lipid formulations. Liposomes can be engineered to express specific surface molecules for cellular targeting and to carry defined cargo (19). Currently, there are a number of therapies available that make use of liposomal delivery methods (20). For example, Doxil $\AA$ uses a liposomal delivery system to improve the targeting of doxorubicin to tumour cells, and has FDA approval for treatment of 
Kaposi's sarcoma, ovarian cancer, metastatic breast cancer and multiple myeloma (21). Clinical trials involving liposomes or EVs are in progress $(19,22)$.

\section{Origin and abundance of EVs in arthritis}

Synovial fluid contains EVs that originate from a variety of local and infiltrating cells within the synovial joint. In one study, platelet-derived EVs were identified as the most abundant type of EVs in synovial fluid from RA and other inflammatory arthritides, and were shown to be scarce in synovial fluid obtained from patients with non-inflammatory osteoarthritis (OA) (23). However, Berckmans et al. reported that the most abundant microvesicles in both RA and non-RA synovial fluid were derived from granulocytes and monocytes, with platelet-derived microvesicles only detectable at low levels (24). Consistent with this, Headland et al. found high levels of neutrophil-derived EVs in RA synovial fluid (25). Meanwhile, another group observed that the majority of EVs in RA synovial fluid were derived from $B$ and T cells, and noted that the levels of EVs derived from $T$ cells in RA synovial fluid were elevated when compared with OA and strongly correlated with levels of rheumatoid factor (26). Conflicting reports such as these could be due to methodological factors - including variations in collection, isolation and analysis of EVs (Table 1). For example, Boilard and colleagues demonstrated that platelet-derived EVs are more readily detected through the presence of CD41, as opposed to CD61 (23), which was used by Berckmans et al. (24) and this might explain their lower estimates. Moreover, methods to avoid platelet activation and aggregation were not uniformly employed across all of these studies. Such inconsistencies highlight the importance of detailed method reporting in studies involving EVs, as well as the inherent limitations that result from an absence of standardised isolation and analysis techniques $(27,28)$.

In terms of abundance, there have been suggestions that RA promotes an increase in EV numbers within the synovial fluid. For example, increased EV concentrations have been observed in synovial fluid from individuals with RA compared to psoriatic arthritis (PsA), but not OA $(26,29)$. In this situation, EV 
abundance in synovial fluid appears a function of cellular activation state rather than cell number as indicated by poor correlations between the numbers of EV and cell counts (26). Treatment of fibroblast-like synoviocytes (FLS) derived from an RA joint with TNF resulted in a large increases in exosome production, whereas FLS derived from an OA joint exhibited minimal release in response to TNF (30). Similarly, normal human FLS have been observed to increase EV production in response to IL-1 $\beta$ stimulation (31).

Whether circulating EVs found within the systemic circulation change in RA is unclear. For instance, one study found that plasma from RA patients contained increased numbers of EVs as well as higher proportions of platelet-derived EVs when compared to healthy controls (32), but another group failed to detect any differences (33). Interestingly, disease-modifying anti-rheumatic drug (DMARD) treatment has been shown to affect circulating microvesicles (34). Specifically, a decrease in the proportion of plasma microvesicles of platelet, monocyte, B, T and endothelial origin in RA patients was observed following 4 weeks of treatment with methotrexate, sulphasalazine and prednisone, and similar changes were also observed in urine. Consistent with this, the authors reported a significant correlation between disease activity and the proportion of plasma and urine microvesicles of platelet, monocyte, B, T and endothelial cell origin. Interestingly, the overall numbers of circulating EVs did not change during DMARD therapy in this study (34). However, others have reported that the number of microvesicles was not significantly different after 8 weeks of treatment with methotrexate, sulphasalazine and prednisolone, despite a reduction in disease activity (35), and plasma platelet-derived EVs numbers were not significantly altered in patients who had undergone treatment with immunosuppressive or biological drugs compared to untreated patients (32).

\section{EVs as drivers of joint inflammation and destruction}

In RA, FLS play key roles in promoting tissue inflammation and damage. Exosomes derived from RA FLS may augment these effector functions, including multiple effects on activated $\mathrm{CD} 4^{+} \mathrm{T}$ cells, such as: reducing activation-induced 
cell death; promoting release of IFN- $y$ and IL-2 from these cells; increasing activity of NF-KB and Akt; and inhibiting caspase-3 and caspase-8 cleavage. These effects were reversed by TNF inhibition (30). EVs isolated from RA FLS have also been associated with degradation of bone and cartilage through direct metalloproteinase activity (36) but also by autocrine induction of matrix metalloproteinase 1 (MMP-1) release from FLS (30). Consistent with this, another group observed that TNF stimulation of RA FLS increased secretion of exosomal miR-221-3p, which negatively regulates bone formation (37), while EVs from normal human FLS stimulated with IL-1 $\beta$ promoted release of glycosaminoglycans from cartilage (31). Finally, exosomes derived from RA (but not OA FLS) contained a membrane-bound form of TNF that can activate NF-KB pathway signalling in recipient FLS in an autocrine, TNF dependent fashion (30).

As well as acting as a source of EVs, RA FLS can be targets for EVs derived from other cells. For example, upon treatment with EVs from activated $T$ cells and monocytes, RA FLS display increased release of not only MMPs, but also cytokines and chemokines, such as IL-6, IL-8, MCP-1, and MCP-2. Interestingly, similar results were observed by stimulating OA FLS and non-diseased FLS, suggesting that FLS are inherently equipped to respond to pro-inflammatory signals from EVs (38). Another group found that exposure of FLS to EVs isolated from RA synovial fluid results in increased transcription of chemokines CXCL-1, CXCL-2, CXCL-3, CXCL-5, and CXCL-6 genes (39). Consistent with this finding, supernatant from FLS treated with EVs caused chemokine-induced migration of human microvascular endothelial cells and angiogenesis in vivo (39).

Although somewhat controversial, as noted earlier, platelet-derived EVs have been reported in the synovial fluid of inflamed joints and thus may contribute to the development of RA. Evidence for this was provided by Boilard et al. who found that platelet-derived EVs from RA synovial fluid caused activation of FLS via the IL-1 receptor and subsequent release of IL-6 and IL-8 (23). Both IL-1a and IL-1 $\beta$ were associated with RA synovial fluid platelet-derived EVs, but IL-1 $\alpha$ was more abundant and was found on the surface of platelet-derived EVs. 
Importantly, blocking both $\mathrm{IL}-1 \alpha$ and IL-1 $\beta$ was required to prevent FLS activation. Interestingly, this study also identified the collagen receptor glycoprotein VI as an important mediator in the genesis of platelet-derived EVs and - in a finding that might be exploited for therapeutic purposes -- showed that loss of glycoprotein $\mathrm{VI}$ significantly reduced arthritic symptoms in the $\mathrm{K} / \mathrm{BxN}$ serum transfer mouse model of RA (23). More recently, using the $\mathrm{K} / \mathrm{BxN}$ serum transfer model, Duchez et al. reported that platelet-derived EVs intravenously injected are preferentially taken up by activated joint neutrophils and that this internalisation is dependent on both platelet-type 12-LO (an enzyme required for metabolising arachidonic acid) and SPLA - IIA (an enzyme involved in releasing lysophospholipids and fatty acids from EV phospholipids) (40). Strikingly, mouse recipients of $\mathrm{K} / \mathrm{BxN}$ serum developed more pronounced joint inflammation when both 12-LO and SPLA - IIA were present, providing further support to a pathogenic role for platelet-derived EVs in arthritis.

EVs may be functionally important, even if the cell of origin is unclear. For example, RA synovial fluid EVs have elevated levels of receptor activator of NFKB (RANK) and RANK-ligandLigand, which can drive osteoclast activity and bone destruction (26). Microvesicles from the plasma of RA patients with high disease activity induced the release of pro-inflammatory IL-1, TNF- $\alpha$, and IL-17 from autologous peripheral blood mononuclear cells (34). Microvesicles from RA plasma also contained elevated levels of $\mathrm{C} 1 \mathrm{q}$, suggesting that circulating microvesicles in RA propagate inflammation through transport of complement components (35).

Immune complexes play an important pathogenic role in RA. EVs can form macromolecular structures in association with immune complexes and such complexes may contribute to joint inflammation. Cloutier et al. identified EVimmune complex aggregates in RA synovial fluid using high-resolution flow cytometry and transmission electron microscopy, which revealed - in addition to the standard microvesicle population of $\sim 100-300 \mathrm{~nm}$ in diameter - larger structures $\sim 700-3,000 \mathrm{~nm}$ in diameter that consisted of both microvesicles and immune complexes (29). This was in contrast to synovial fluid from patients with 
psoriatic arthritis, which contained a single distinct population of $100-300 \mathrm{~nm}$ microvesicles. The majority of immune complexes in RA synovial fluid were associated with microvesicles (including platelet-derived microvesicles), and contained citrullinated autoantigens, such as vimentin and fibrinogen. Plateletderived microvesicles containing citrullinated proteins bound IgG from RA synovial fluid, but not IgG from psoriatic arthritis synovial fluid, to form microvesicle-immune complex structures in vitro, suggesting that anti-citrullinated protein antibodies in RA synovial fluid facilitate the formation of microvesicleimmune complexes. (29). Upon incubation with microvesicle-immune complexes isolated from RA synovial fluid, human neutrophils released pro-inflammatory leukotrienes more robustly compared to incubation with microvesicles alone (29). Whether synovial fluid exosomes are also able to complex with immune complexes remains unknown, but the observation that synovial fluid exosomes also contain citrullinated peptides suggests this possibility (41).

Drawing together the above findings, we propose a model (Fig. 3) wherein immune cells infiltrate the RA joint and - in conjunction with resident synoviocytes such as FLS =- release large numbers of EVs into the synovial tissue and surrounding synovial fluid. Subsequently, synovial fluid EVs might trigger synoviocytes to release pro-inflammatory cytokines and chemokines that promote cell proliferation and survival as well as angiogenesis, leading to further immune cell infiltration. In this way, a positive feedback loop mediated by EVs might sustain joint inflammation.

\section{Protective roles for EVs during joint inflammation}

Although much work on EVs in RA indicates a pro-inflammatory role for EVs, there is also growing evidence that EVs protect joints. For example, MartínezLorenzo et al. found that the depletion of EVs abrogated the ability of synovial fluid to induce cell death in immortalised T cells, suggesting that EVs might play a role in limiting $T$ cell driven inflammation (42). These investigators observed that synovial fluid from RA patients contains relatively few exosomes compared to synovial fluid from patients with traumatic arthritis and that RA synovial fluid 
displays a correspondingly reduced ability to initiate apoptosis in synovial T-cells (42). Meanwhile, Headland et al. described a role for neutrophil-derived EVs in mitigating cartilage damage (25). They showed that neutrophil-derived EVs contain the anti-inflammatory protein Annexin A1 and are present in high abundance in RA synovial fluid. Neutrophils derived from healthy blood were stimulated with TNF- $\alpha$, and EVs similar to those found in RA synovial fluid were generated. These EVs were able to act upon chondrocytes to limit IL-1 $\beta$ mediated repression of cartilage matrix proteins, increase transcription of TGF$\beta 1$ (which stimulates extracellular matrix accumulation), inhibit release of IL-8 and $\mathrm{PGE}_{2}$ (which are involved in cartilage degradation), and limit chondrocyte apoptosis. Blocking the Annexin A1 receptor, FPR2/ALX, abrogated these protective effects, providing further support for the importance of EV-bound Annexin A1. Interestingly, using rat cartilage explants, the authors showed that neutrophil-derived EVs migrate into cartilage, and that this migration was more pronounced when cartilage was pre-stimulated with IL-1 $1 \beta$, whereas monocytederived EVs did not migrate into cartilage. Furthermore, in mouse models of RA, intra-articular injections of EVs from TNF-stimulated neutrophils abrogated loss of sulphated glycosaminoglycans from cartilage, while mice deficient in TMEM16F (a protein involved in EV formation) had greater loss of sulphated glycosaminoglycans (25). Taken together, these findings support a model (Fig. 3) wherein inflammation within cartilage might facilitate infiltration of neutrophilderived EVs, which could interact with recipient chondrocytes and protect against further cartilage degradation in RA. Such a model obviously runs counter to a large body of evidence indicating that neutrophils act to promote inflammation and joint damage, but is consistent with recent work indicating an important role for neutrophils in resolving inflammation (43).

EVs may also help to protect joints in conditions other than RA. In one recent study, neutrophil-derived EVs hastened the resolution of gout (44). Specifically, Cumpelik and colleagues observed that in a monosodium urate (MSU) induced murine model of gout, an increase in IL-1 $\beta$ was closely followed by an increase in neutrophil-derived EVs. It has previously been shown that MSU-induced IL-1 $\beta$ 
production via the inflammasome is regulated by complement C5a (45), and Cumpelik et al. interestingly discovered that neutrophil-derived EVs from human gout exudates suppressed complement $\mathrm{C} 5 \mathrm{a}$-mediated inflammasome activation in recipient macrophages (44). This suggests a negative feedback model wherein neutrophil-derived EVs help to limit the extent of joint inflammation. Along similar lines, EVs derived from mature osteoclasts have been found to inhibit osteoclast differentiation in 1,25-dihydroxyvitamin D3 stimulated bone marrow cultures (46). In this case, inhibition was paradoxically dependent on the presence of EV-associated RANK, which may competitively bind RANKL and thereby prevent RANK-RANKL interactions in precursor cells to attenuate osteoclast differentiation (46). Finally, EVs may also help to promote joint repair, since intra-articular injection of exosomes from mesenchymal stem cells - which have important roles in tissue repair $(47,48)$ and are normally found within the synovium $(49,50)$-- was demonstrated to promote cartilage repair in a rat model of osteochondral damage (51).

Finally, EVs might also facilitate the beneficial effects of some arthritis therapies. In one study of immortalised synovial cells, treatment with methotrexate and sulfasalazine induced changes in the protein content of released exosomes (52). Interestingly, many of the altered exosomal proteins had immunosuppressive functions, raising the possibility that treatment-induced EVs might augment the response to certain DMARDs.

\section{EVs as biomarkers in arthritis}

As noted earlier, EVs are proving of interest as novel biomarkers in a variety of diseases. One study in RA identified dysregulated long noncoding RNAs HOTAIR and LUST = in circulating exosomes obtained from the serum of patients with established RA, compared to healthy donors (53). Other circulating biomarker studies in RA have focused on miRNAs, but these all assessed total serum or plasma RNA, without enriching for EVs. Given that the majority of circulating miRNAs in plasma and serum are associated with EVs and methods used to isolate circulating miRNAs also enrich for EV miRNAs $(54,55)$, these 
studies only provide indirect information on EV miRNA content. Several circulating miRNAs appear to be promising biomarkers in RA. For example, one study identified three miRNAs $=-$ miR-24, miR-30a-5p and miR-125a-5p $=$ - that in combination were able to differentiate patients with RA from healthy controls and patients with systemic lupus erythematosus or OA. Furthermore, miR-24 levels were found to correlate with the disease activity score (DAS-28), Creactive protein, visual analogue pain scales and erythrocyte sedimentation rate (56).

Other studies show that circulating miRNAs might help to predict the response to biologic agents. For example, levels of miR-23-3p and miR-223-3p in serum were good indicators of response to anti-TNFa/DMARD combination therapy (57), while high pre-treatment serum levels of miR-125b were associated with a good clinical response to rituximab (58). Inclusion of an EV purification step in such miRNA biomarker studies might enrich for disease-specific miRNAs and improve the signal-to-noise ratio by eliminating more abundant circulating RNAs (e.g. ribosomal RNA) (55).

Apart from RNA, other components of EVs, such as protein, lipids and metabolites might also prove to be useful biomarkers in RA, but minimal research has been conducted to date in this area.

\section{Therapeutic use of EVs in inflammatory joint disease}

Engineering of EVs for treatment of inflammatory joint disease is currently being explored using several different approaches in pre-clinical animal models (Fig. 4). In the collagen-induced arthritis (CIA) mouse model, intravenous injection of exosomes from bone marrow dendritic cells (BMDCs) =- either transduced to express a viral-encoded homologue of IL-10, or treated with recombinant murine IL-10 =- dramatically repressed the onset of arthritis (59). Moreover, these exosomes were also able to reduce the severity of established CIA. Interestingly, these effects were not observed with injection of IL-10, suggesting that the role of IL-10 might not be as a direct ligand in vivo, but rather to promote the production of anti-inflammatory exosomes (59). Similar results in CIA have 
been observed using a single systemic injection of EVs generated from BMDCs genetically engineered to express Fas Ligand, IL-4, the immunosuppressing enzyme indoleamine 2,3-dioxygenase, or its inducer, cytotoxic T lymphocyteassociated antigen-4-immunoglobulin (60).

Loading of EVs with other anti-inflammatory molecules may hold promise for the treatment of joint inflammation. For example, recent work suggests that EVs containing SOCS proteins may regulate pro-inflammatory STAT signalling, which is increased in RA. Exposing alveolar macrophages to IL-10 or PGE2 rapidly increased SOCS1 and SOCS3 secretion in exosomes and microvesicles respectively. By treating alveolar epithelial cells with SOCS containing EVs, STAT signalling was successfully suppressed (12). In this way, SOCS-loaded EVs generated from autologous cells could represent a novel therapeutic strategy for reducing joint inflammation. Finally, as mechanisms for selectively loading RNAs into EVs are being discovered (61), the possibility of loading EVs with therapeutic siRNAs might also become an option in arthritis.

As noted earlier, the ability of EVs to deliver a defined molecular cargo is being exploited in liposome-based therapeutics. In one study, liposomes were loaded with a membrane-bound form of APO2L/TRAIL and then injected into the knee in a rabbit model of RA (62). This greatly reduced joint inflammation, with decreased inflammatory infiltrate, vascularity and exudate. Another group engineered liposomes to contain not only methotrexate but also surface bound folate (63). The latter modification targeted the liposomes to activated macrophages and when injected intraperitoneally, CIA was much less pronounced compared with methotrexate injection alone.

\section{Conclusions}

Research interest in EVs has increased dramatically in recent years. Although much work has occurred in the fields of cancer biology and oncology, efforts to improve our understanding of EVs in RA are gaining momentum. High sensitivity 'omics' approaches to detect changes in protein, RNA, lipid and metabolite profiles of EVs may facilitate diagnosis and selection of therapies. Modulating 
EV biogenesis or uptake might also hold promise for treating RA. Potential molecular targets include 12-LO and $\mathrm{SPLA}_{2}-\mathrm{IIA}$, or glycoprotein $\mathrm{VI}$ to block uptake or biogenesis respectively. An alternative strategy might be to prevent the formation of autoantibodies with EV-associated citrullinated peptides in order to reduce EV-immune complex formation. Finally, and excitingly, EVs may provide a new way to deliver and better target therapeutic agents in RA.

\section{References}

1. Buzas EI, Gyorgy B, Nagy G, Falus A, Gay S. Emerging role of extracellular vesicles in inflammatory diseases. Nat Rev Rheumatol. 2014;10:356-64.

2. Gardiner C, Vizio DD, Sahoo S, Théry C, Witwer KW, Wauben M, et al.

Techniques used for the isolation and characterization of extracellular vesicles: results of a worldwide survey. J Extracell Vesicles. 2016;5:32945.

3. Coleman BM, Hill AF. Extracellular vesicles - Their role in the packaging and spread of misfolded proteins associated with neurodegenerative diseases (review). Semin Cell Dev Biol. 2015;40:89-96.

4. Peinado H, Aleckovic M, Lavotshkin S, Matei I, Costa-Silva B, Moreno-Bueno $\mathrm{G}$, et al. Melanoma exosomes educate bone marrow progenitor cells toward a prometastatic phenotype through MET. Nat Med. 2012;18:883-91.

$5 . \quad$ Valadi H, Ekstrom K, Bossios A, Sjostrand M, Lee JJ, Lotvall JO. Exosomemediated transfer of mRNAs and microRNAs is a novel mechanism of genetic exchange between cells (letter). Nat Cell Biol. 2007;9:654-59.

6. Alexander M, Hu R, Runtsch MC, Kagele DA, Mosbruger TL, Tolmachova T, et al. Exosome-delivered microRNAs modulate the inflammatory response to endotoxin. Nature Communications. 2015;6:7321.

7. Vega VL, Rodríguez-Silva M, Frey T, Gehrmann M, Diaz JC, Steinem C, et al. Hsp70 Translocates into the Plasma Membrane after Stress and Is Released into the Extracellular Environment in a Membrane-Associated Form that Activates Macrophages. J Immunol. 2008;180:4299-307.

8. Cossetti C, Iraci N, Mercer Tim R, Leonardi T, Alpi E, Drago D, et al. Extracellular Vesicles from Neural Stem Cells Transfer IFN- $\gamma$ via Ifngr1 to Activate Stat1 Signaling in Target Cells. Mol Cell. 2014;56:193-204.

9. Bretz NP, Ridinger J, Rupp AK, Rimbach K, Keller S, Rupp C, et al. Body fluid exosomes promote secretion of inflammatory cytokines in monocytic cells via Tolllike receptor signaling. J Biol Chem. 2013;288:36691-702.

10. Fabbri M, Paone A, Calore F, Galli R, Gaudio E, Santhanam R, et al. MicroRNAs bind to Toll-like receptors to induce prometastatic inflammatory response. Proc Natl Acad Sci U S A. 2012;109:E2110-E16.

11. Liu X, Croker BA, Campbell IK, Gauci SJ, Alexander WS, Tonkin BA, et al. Key role of suppressor of cytokine signaling 3 in regulating gp130 cytokine-induced 
signaling and limiting chondrocyte responses during murine inflammatory arthritis. Arthritis Rheumatol. 2014;66:2391-402.

12. Bourdonnay E, Zasłona Z, Penke LRK, Speth JM, Schneider DJ, Przybranowski $\mathrm{S}$, et al. Transcellular delivery of vesicular SOCS proteins from macrophages to epithelial cells blunts inflammatory signaling. J Exp Med. 2015;212:729-42. 13. Szajnik M, Czystowska M, Szczepanski MJ, Mandapathil M, Whiteside TL. Tumor-Derived Microvesicles Induce, Expand and Up-Regulate Biological Activities of Human Regulatory T Cells (Treg). PLoS One. 2010;5:e11469.

14. Skog J, Wurdinger T, van Rijn S, Meijer D, Gainche L, Sena-Esteves M, et al. Glioblastoma microvesicles transport RNA and protein that promote tumor growth and provide diagnostic biomarkers (letter). Nat Cell Biol. 2008;10:1470-76. 15. Melo SA, Luecke LB, Kahlert C, Fernandez AF, Gammon ST, Kaye J, et al. Glypican-1 identifies cancer exosomes and detects early pancreatic cancer. Nature. 2015;523:177-82.

16. Cheng L, Doecke JD, Sharples RA, Villemagne VL, Fowler CJ, Rembach A, et al. Prognostic serum miRNA biomarkers associated with Alzheimer's disease shows concordance with neuropsychological and neuroimaging assessment. Mol Psychiatry. 2014;20:1188-96.

17. Alvarez-Erviti L, Seow Y, Yin H, Betts C, Lakhal S, Wood MJA. Delivery of siRNA to the mouse brain by systemic injection of targeted exosomes (letter). Nat Biotech. 2011;29:341-45.

18. Ohno S-i, Takanashi M, Sudo K, Ueda S, Ishikawa A, Matsuyama N, et al. Systemically Injected Exosomes Targeted to EGFR Deliver Antitumor MicroRNA to Breast Cancer Cells. Mol Ther. 2013;21:185-91.

19. Allen TM, Cullis PR. Liposomal drug delivery systems: From concept to clinical applications (review). Adv Drug Deliv Rev. 2013;65:36-48.

20. Pattni BS, Chupin VV, Torchilin VP. New Developments in Liposomal Drug Delivery (review). Chem Rev. 2015;115:10938-66.

21. Barenholz Y. Doxil@ - The first FDA-approved nano-drug: Lessons learned (review). J Control Release. 2012;160:117-34.

22. Lener T, Gioma M, Aigner L, Börger V, Buzas E, Camussi G, et al. Applying extracellular vesicles based therapeutics in clinical trials - an ISEV position paper. 2015;4:30087.

23. Boilard E, Nigrovic PA, Larabee K, Watts GF, Coblyn JS, Weinblatt ME, et al. Platelets amplify inflammation in arthritis via collagen-dependent microparticle production. Science. 2010;327:580-3.

24. Berckmans RJ, Nieuwland R, Tak PP, Böing AN, Romijn FP, Kraan MC, et al. Cell - derived microparticles in synovial fluid from inflamed arthritic joints support coagulation exclusively via a factor VII-dependent mechanism. Arthritis Rheum. 2002;46:2857-66.

25. Headland SE, Jones HR, Norling LV, Kim A, Souza PR, Corsiero E, et al. Neutrophil-derived microvesicles enter cartilage and protect the joint in inflammatory arthritis. Sci Transl Med. 2015;7:315ra190. 
26. György B, Szabó TG, Turiák L, Wright M, Herczeg P, Lédeczi Z, et al. Improved Flow Cytometric Assessment Reveals Distinct Microvesicle (Cell-Derived Microparticle) Signatures in Joint Diseases. PLoS One. 2012;7:e49726.

27. Witwer KW, Buzás EI, Bemis LT, Bora A, Lässer C, Lötvall J, et al.

Standardization of sample collection, isolation and analysis methods in extracellular vesicle research. J Extracell Vesicles. 2013;2:20360.

28. Lotvall J, Hill AF, Hochberg F, Buzas EI, Di Vizio D, Gardiner C, et al. Minimal experimental requirements for definition of extracellular vesicles and their functions: a position statement from the International Society for Extracellular Vesicles (editorial). J Extracell Vesicles. 2014;3:26913.

29. Cloutier N, Tan S, Boudreau LH, Cramb C, Subbaiah R, Lahey L, et al. The exposure of autoantigens by microparticles underlies the formation of potent inflammatory components: the microparticle-associated immune complexes. EMBO Mol Med. 2013;5:235-49.

30. Zhang H-G, Liu C, Su K, Yu S, Zhang L, Zhang S, et al. A Membrane Form of TNF- $\alpha$ Presented by Exosomes Delays T Cell Activation-Induced Cell Death. J Immunol. 2006;176:7385-93.

31. Kato T, Miyaki S, Ishitobi H, Nakamura Y, Nakasa T, Lotz MK, et al. Exosomes from IL-1 $\beta$ stimulated synovial fibroblasts induce osteoarthritic changes in articular chondrocytes. Arthritis Res Ther. 2014;16:R163.

32. Sellam J, Proulle V, Jüngel A, Ittah M, Miceli Richard C, Gottenberg J-E, et al. Increased levels of circulating microparticles in primary Sjögren's syndrome, systemic lupus erythematosus and rheumatoid arthritis and relation with disease activity. Arthritis Res Ther. 2009;11:R156-R56.

33. Biró É, Nieuwland R, Tak PP, Pronk LM, Schaap MCL, Sturk A, et al. Activated complement components and complement activator molecules on the surface of cell - derived microparticles in patients with rheumatoid arthritis and healthy individuals. Ann Rheum Dis. 2007;66:1085-92.

34. Viñuela-Berni V, Doníz-Padilla L, Figueroa-Vega N, Portillo-Salazar H, AbudMendoza C, Baranda L, et al. Proportions of several types of plasma and urine microparticles are increased in patients with rheumatoid arthritis with active disease. Clin Exp Immunol. 2015;180:442-51.

35. van Eijk IC, Tushuizen ME, Sturk A, Dijkmans BAC, Boers M, Voskuyl AE, et al. Circulating microparticles remain associated with complement activation despite intensive anti-inflammatory therapy in early rheumatoid arthritis. Ann Rheum Dis. 2010;69:1378-82.

36. Lo Cicero A, Majkowska I, Nagase H, Di Liegro I, Troeberg L. Microvesicles shed by oligodendroglioma cells and rheumatoid synovial fibroblasts contain aggrecanase activity. Matrix Biol. 2012;31:229-33.

37. Maeda Y, Farina NH, Matzelle MM, Fanning PJ, Lian JB, Gravallese EM. Synovium-Derived MicroRNAs Regulate Bone Pathways in Rheumatoid Arthritis. J Bone Miner Res. 2016.

38. Distler JHW, Jüngel A, Huber LC, Seemayer CA, Reich CF, Gay RE, et al. The induction of matrix metalloproteinase and cytokine expression in synovial 
fibroblasts stimulated with immune cell microparticles. Proc Natl Acad Sci U S A. 2005;102:2892-97.

39. Reich N, Beyer C, Gelse K, Akhmetshina A, Dees C, Zwerina J, et al. Microparticles stimulate angiogenesis by inducing ELR(+) CXC-chemokines in synovial fibroblasts. J Cell Mol Med. 2011;15:756-62.

40. Duchez A-C, Boudreau LH, Bollinger J, Belleannée C, Cloutier N, Laffont B, et al. Platelet microparticles are internalized in neutrophils via the concerted activity of 12-lipoxygenase and secreted phospholipase A2-IIA. Proc Natl Acad Sci U S A. 2015;112:E3564-E73.

41. Skriner K, Adolph K, Jungblut PR, Burmester GR. Association of citrullinated proteins with synovial exosomes. Arthritis Rheum. 2006;54:3809-14.

42. Martínez-Lorenzo MJ, Anel A, Saez-Gutierrez B, Royo-Cañas M, Bosque A, Alava MA, et al. Rheumatoid synovial fluid T cells are sensitive to APO2L/TRAIL. Clin Immunol. 2007;122:28-40.

43. Jones HR, Robb CT, Perretti M, Rossi AG. The role of neutrophils in inflammation resolution. Semin Immunol. 2016;28:137-45.

44. Cumpelik A, Ankli B, Zecher D, Schifferli JA. Neutrophil microvesicles resolve gout by inhibiting C5a-mediated priming of the inflammasome. Ann Rheum Dis.

2016;75:1236-45.

45. An LL, Mehta P, Xu L, Turman S, Reimer T, Naiman B, et al. Complement C5a

potentiates uric acid crystal-induced IL-1beta production. Eur J Immunol. 2014;44:3669-79.

46. Huynh N, VonMoss L, Smith D, Rahman I, Felemban MF, Zuo J, et al.

Characterization of Regulatory Extracellular Vesicles from Osteoclasts. J Dent Res. 2016;95:673-79.

47. Lai RC, Yeo RWY, Lim SK. Mesenchymal stem cell exosomes (review). Semin Cell Dev Biol. 2015;40:82-88.

48. Toh WS, Lai RC, Hui JHP, Lim SK. MSC exosome as a cell-free MSC therapy for cartilage regeneration: Implications for osteoarthritis treatment (review). Semin Cell Dev Biol. 2016.

49. De Bari C, Dell'Accio F, Tylzanowski P, Luyten FP. Multipotent mesenchymal stem cells from adult human synovial membrane. Arthritis Rheum. 2001;44:192842.

50. Ando W, Kutcher JJ, Krawetz R, Sen A, Nakamura N, Frank CB, et al. Clonal analysis of synovial fluid stem cells to characterize and identify stable mesenchymal stromal cell/mesenchymal progenitor cell phenotypes in a porcine model: a cell source with enhanced commitment to the chondrogenic lineage. Cytotherapy. 2014;16:776-88.

51. Zhang S, Chu WC, Lai RC, Lim SK, Hui JHP, Toh WS. Exosomes derived from human embryonic mesenchymal stem cells promote osteochondral regeneration. Osteoarthritis Cartilage. 2016;24:2135-40.

52. Tsuno H, Suematsu N, Sato T, Arito M, Matsui T, Iizuka N, et al. Effects of methotrexate and salazosulfapyridine on protein profiles of exosomes derived from a human synovial sarcoma cell line of SW982. Proteomics Clin Appl. 2015;10:16471. 
53. Song J, Kim D, Han J, Kim Y, Lee M, Jin EJ. PBMC and exosome-derived Hotair is a critical regulator and potent marker for rheumatoid arthritis. Clin Exp Med. 2015;15:121-26.

54. Gallo A, Tandon M, Alevizos I, Illei GG. The Majority of MicroRNAs Detectable in Serum and Saliva Is Concentrated in Exosomes. PLoS One. 2012;7:e30679.

55. Cheng L, Sharples RA, Scicluna BJ, Hill AF. Exosomes provide a protective and enriched source of miRNA for biomarker profiling compared to intracellular and cell-free blood. J Extracell Vesicles. 2014;3:23743.

56. Murata K, Furu M, Yoshitomi H, Ishikawa M, Shibuya H, Hashimoto M, et al. Comprehensive microRNA Analysis Identifies miR-24 and miR-125a-5p as Plasma Biomarkers for Rheumatoid Arthritis. PLoS One. 2013;8:e69118.

57. Castro-Villegas C, Perez-Sanchez C, Escudero A, Filipescu I, Verdu M, RuizLimon $\mathrm{P}$, et al. Circulating miRNAs as potential biomarkers of therapy effectiveness in rheumatoid arthritis patients treated with anti-TNFalpha. Arthritis Res Ther. 2015;17:49.

58. Duroux-Richard I, Pers Y-M, Fabre S, Ammari M, Baeten D, Cartron G, et al. Circulating miRNA-125b Is a Potential Biomarker Predicting Response to Rituximab in Rheumatoid Arthritis. Mediators Inflamm. 2014;2014:342524.

59. Kim S-H, Lechman ER, Bianco N, Menon R, Keravala A, Nash J, et al. Exosomes Derived from IL-10-Treated Dendritic Cells Can Suppress Inflammation and Collagen-Induced Arthritis. J Immunol. 2005;174:6440-48.

60. Robbins PD, Dorronsoro A, Booker CN. Regulation of chronic inflammatory and immune processes by extracellular vesicles (review). J Clin Invest. 2016;126:1173-80.

61. Villarroya-Beltri C, Baixauli F, Gutiérrez-Vázquez C, Sánchez-Madrid F, Mittelbrunn M. Sorting it out: Regulation of exosome loading (review). Semin Cancer Biol. 2014;28:3-13.

62. Martinez-Lostao L, Garcí'a-Alvarez Fc, Basáñez G, Alegre-Aguarón E, Desportes P, Larrad L, et al. Liposome-bound AP02L/TRAIL is an effective treatment in a rabbit model of rheumatoid arthritis. Arthritis Rheum.

2010;62:2272-82.

63. Nogueira E, Lager F, Le Roux D, Nogueira P, Freitas J, Charvet C, et al. Enhancing methotrexate tolerance with folate tagged liposomes in arthritic mice. J Biomed Nanotechnol. 2015;11:2243-52.

64. Aatonen MT, Öhman T, Nyman TA, Laitinen S, Grönholm M, Siljander PR-M. Isolation and characterization of platelet-derived extracellular vesicles. J Extracell Vesicles. 2014;3:24692.

65. Boere J, van de Lest CHA, Libregts SFWM, Arkesteijn GJA, Geerts WJC, Nolte-, et al. Synovial fluid pretreatment with hyaluronidase facilitates isolation of CD44+ extracellular vesicles. J Extracell Vesicles. 2016;5:31751.

66. Lacroix R, Robert S, Poncelet P, Dignat-George F. Overcoming Limitations of Microparticle Measurement by Flow Cytometry (review). Semin Thromb Hemost. 2010;36:807-18. 


\section{Figure legends}

Figure 1. Biogenesis of exosomes and microvesicles Invagination of the late endosome forms intraluminal vesicles ranging from 30$150 \mathrm{~nm}$. Fusion of the late endosome (also known as a multi-vesicular body) with the plasma membrane releases the vesicles into the extracellular milieu, which are therefore termed 'exosomes'. Microvesicles are formed by outward protrusion of the plasma membrane and are typically larger than exosomes at $100-1,000 \mathrm{~nm}$. (Note: some groups use the term 'microparticle' synonymously with 'microvesicle', whereas others use 'microparticle' as a general term that encompasses exosomes, microvesicles and non-vesicular particulate of similar size and/or density. To avoid confusion, we will use microvesicle throughout this review). Both exosomes and microvesicles contain a range of molecules from the cell of origin, including proteins and RNAs.

Figure 2. Mechanisms of extracellular vesicle interaction with recipient cells

EVs can interact with recipient cells in a number of ways. (a) EV membrane proteins (including TNF) are capable of stimulating recipient cells via cognate receptors on the surface of target cells. (b) Direct fusion of an EV membrane and the plasma membrane of a recipient cell results in release of EV cargo into the cytosol. (c) i) Endocytosis of EVs can lead to fusion of the endosomal and EV membranes to release EV contents into the cytosol. ii) Alternatively, the membrane of an endocytosed EV can degrade upon endosomal acidification, resulting in release of $\mathrm{EV}$ cargo which can interact with endosomal receptors, such as TLR7/8.

\section{Figure 3. Potential roles for extracellular vesicles in joint ilnflammation}

Resident synoviocytes and infiltrating immune cells release EVs into synovial fluid and synovial tissue. Synovial EVs contain molecules capable of driving inflammation and joint destruction. Furthermore, anti-citrullinated peptide antibodies recognise EV-associated citrullinated peptides to form potent proinflammatory complexes. A positive feedback loop is proposed, whereby EVs derived from synoviocytes and various infiltrating leukocytes trigger proinflammatory responses in resident synoviocytes, including fibroblast-like synoviocytes, that leads to synovial hypertrophy, angiogenesis and further immune cell infiltration. Conversely, some EVs may regulate joint inflammation. For example, neutrophil derived EVs can migrate into cartilage and stimulate protective effects in recipient chondrocytes, including transcription of genes involved in cartilage repair.

Figure 4. Generation of anti-inflammatory extracellular vesicles and liposomes for the treatment of inflammatory arthritis

(a) Cells genetically modified to express anti-inflammatory genes produce EVs with anti-inflammatory properties. (b) Cells stimulated to generate endogenously-derived EVs containing an anti-inflammatory cargo. (c) Synthetic 
liposomes deliver drugs by integrating molecules into the liposome membrane that target an encapsulated drug to a specific cell type.
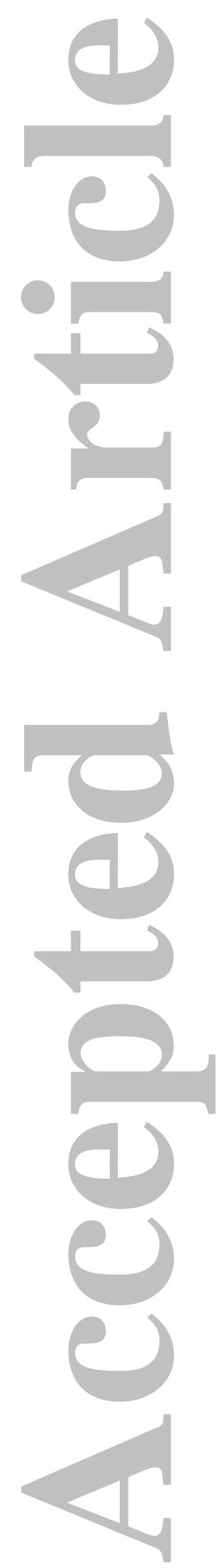
Table 1. Substantial methodological variations explain discordant results across 4 studies investigating EV origins in synovial fluid.

\begin{tabular}{|c|c|c|c|c|c|c|c|c|}
\hline Study & Predominant EV origin & $\begin{array}{c}\text { Anti- } \\
\text { coagulant }{ }^{1} \\
\text { used? }\end{array}$ & $\begin{array}{l}\text { Hyaluronidase }{ }^{2} \\
\text { used? }\end{array}$ & Sample preparation ${ }^{3}$ & EV origins assessed & $\begin{array}{l}\text { Lineage } \\
\text { marker }^{4}\end{array}$ & Flow cytometer ${ }^{5}$ & Comments \\
\hline $\begin{array}{l}\text { Boilard et } \\
\text { al. (23) }\end{array}$ & Platelet & No & No & $\begin{array}{l}2 \times 600 x g, 30 \text { mins (depletes cells) } \\
\text { Supernatant analysed }\end{array}$ & $\begin{array}{l}\text { T cell } \\
\text { Monocyte/Macrophage } \\
\text { Granulocyte/Neutrophil } \\
\text { Platelet }\end{array}$ & $\begin{array}{l}\text { CD3 } \\
\text { CD14 } \\
\text { CD15 } \\
\text { CD41 }\end{array}$ & BD FACSCanto & $\begin{array}{l}\text { Synovial fluid analysed neat following depletion of cells } \\
\text { A combination of exosomes, microvesicles and apoptotic } \\
\text { bodies likely in preparation } \\
\text { High levels of platelet-derived EVs were detected in synovia } \\
\text { fluid using CD41 as a platelet lineage marker, as opposed to } \\
\text { CD61 where negligible levels were observed }\end{array}$ \\
\hline $\begin{array}{l}\text { Berckmans } \\
\text { et al. }(24)\end{array}$ & e/Macrophage & $\begin{array}{l}\text { Yes } \\
\text { (sodium } \\
\text { citrate) }\end{array}$ & No & $\begin{array}{l}\text { 1,550xg, } 20 \text { mins (depletes cells } \\
\text { and apoptotic bodies) } \\
\text { Supernatant centrifuged } 17,570 x g, \\
15 \text { mins (pellets microvesicles) } \\
\begin{array}{l}\text { Microvesicle enriched pellet } \\
\text { analysed }\end{array}\end{array}$ & $\begin{array}{l}\text { T helper cell } \\
\text { T suppressor cell } \\
\text { Monocyte/Macrophage } \\
\text { B cell } \\
\text { Platelet } \\
\text { Granulocyte/Neutrophil } \\
\text { Erythrocyte }\end{array}$ & $\begin{array}{l}\text { CD4 } \\
\text { CD8 } \\
\text { CD14 } \\
\text { CD20 } \\
\text { CD61 } \\
\text { CD66b } \\
\text { Glycophorin A }\end{array}$ & BD FACScan & $\begin{array}{l}\text { Preparation enriched for microvesicles } \\
\text { Inhibition of platelet activation by sodium citrate may reduce } \\
\text { levels of platelet-derived EVs } \\
\text { Low levels of the platelet lineage marker CD61 is described } \\
\text { on platelet-derived EVs in synovial fluid (see ref (23)) }\end{array}$ \\
\hline $\begin{array}{l}\text { Headland } \\
\text { et al. }(25)\end{array}$ & yte/Neutrophil & No & Yes & $\begin{array}{l}3,000 x g, 25 \text { mins (depletes cells } \\
\text { and apoptotic bodies) } \\
\text { Supernatant centrifuged } 10,000 x g \text {, } \\
10 \text { min (depletes microvesicles) } \\
\text { Supernatant analysed }\end{array}$ & $\begin{array}{l}\text { T cell } \\
\text { Monocyte/Macrophage } \\
\text { Granulocyte/Neutrophil }\end{array}$ & $\begin{array}{l}\text { CD3 } \\
\text { CD14 } \\
\text { CD66b }\end{array}$ & $\begin{array}{l}\text { Amnis } \\
\text { ImageStreamX } \\
\text { Mk II }\end{array}$ & $\begin{array}{l}\text { Synovial fluid analysed neat following depletion of cells, } \\
\text { apoptotic bodies and dense microvesicles } \\
\text { Hyaluronidase treatment may have depleted microvesicles in } \\
\text { supernatant following centrifugation at } 10,000 \mathrm{xg} \\
\text { Preparation likely to predominately contain exosomes } \\
\text { Use of a pan EV label (BODIPY-maleimide dye) may have } \\
\text { prevented false positives events being identified }\end{array}$ \\
\hline $\begin{array}{l}\text { György et } \\
\text { al. (26) }\end{array}$ & B cell & No & No & $\begin{array}{l}\text { 650xg, } 20 \text { mins (depletes cells) } \\
\text { Supernatant analysed }\end{array}$ & $\begin{array}{l}\text { T cell } \\
\text { T helper cell } \\
\text { T suppressor cell } \\
\text { Monocyte/Macrophage } \\
\text { B cell } \\
\text { Platelet }\end{array}$ & $\begin{array}{l}\text { CD3 } \\
\text { CD4 } \\
\text { CD8 } \\
\text { CD14 } \\
\text { CD19 } \\
\text { CD41a }\end{array}$ & BD FACSCalibur & $\begin{array}{l}\text { Synovial fluid analysed neat following depletion of cells } \\
\text { A combination of exosomes, microvesicles and apoptotic } \\
\text { bodies likely in preparation } \\
\text { Differential detergent lysis used to remove false-positive } \\
\text { events }\end{array}$ \\
\hline
\end{tabular}

${ }^{1}$ Platelet aggregation increases EV production (see ref (64))
${ }^{3}$ Hyaluronidase treatment of synovial fluid can influence levels of EVs in preparations (see ref (65))

${ }^{3}$ Centrifugal force, duration, and whether EVs are analysed with or without selective enrichment affects type and number of EVs present (see ref (27))

${ }_{5}^{4}$ Lineage markers and antibody clones can vary in ability to accurately detect EVs (see ref (23))

${ }_{5}^{5}$ Ability to detect EVs by flow cytometry can vary depending on instrument and calibration settings (see ref (66))

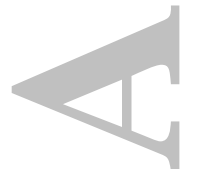




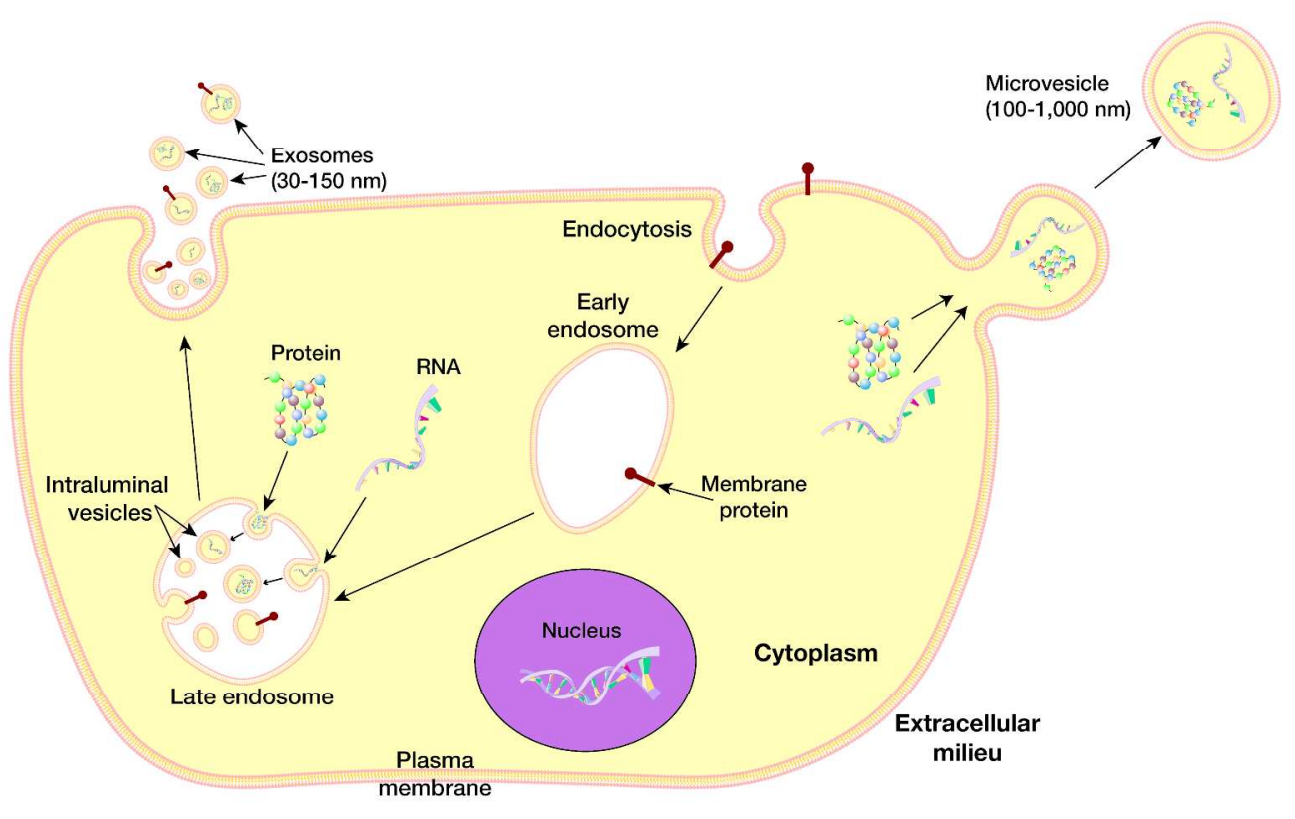

$301 \times 188 \mathrm{~mm}(300 \times 300 \mathrm{DPI})$

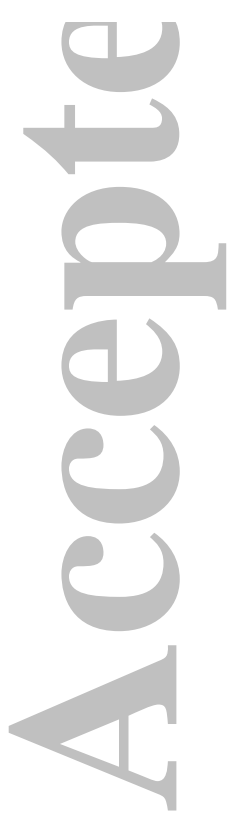

John Wiley \& Sons

This article is protected by copyright. All rights reserved. 

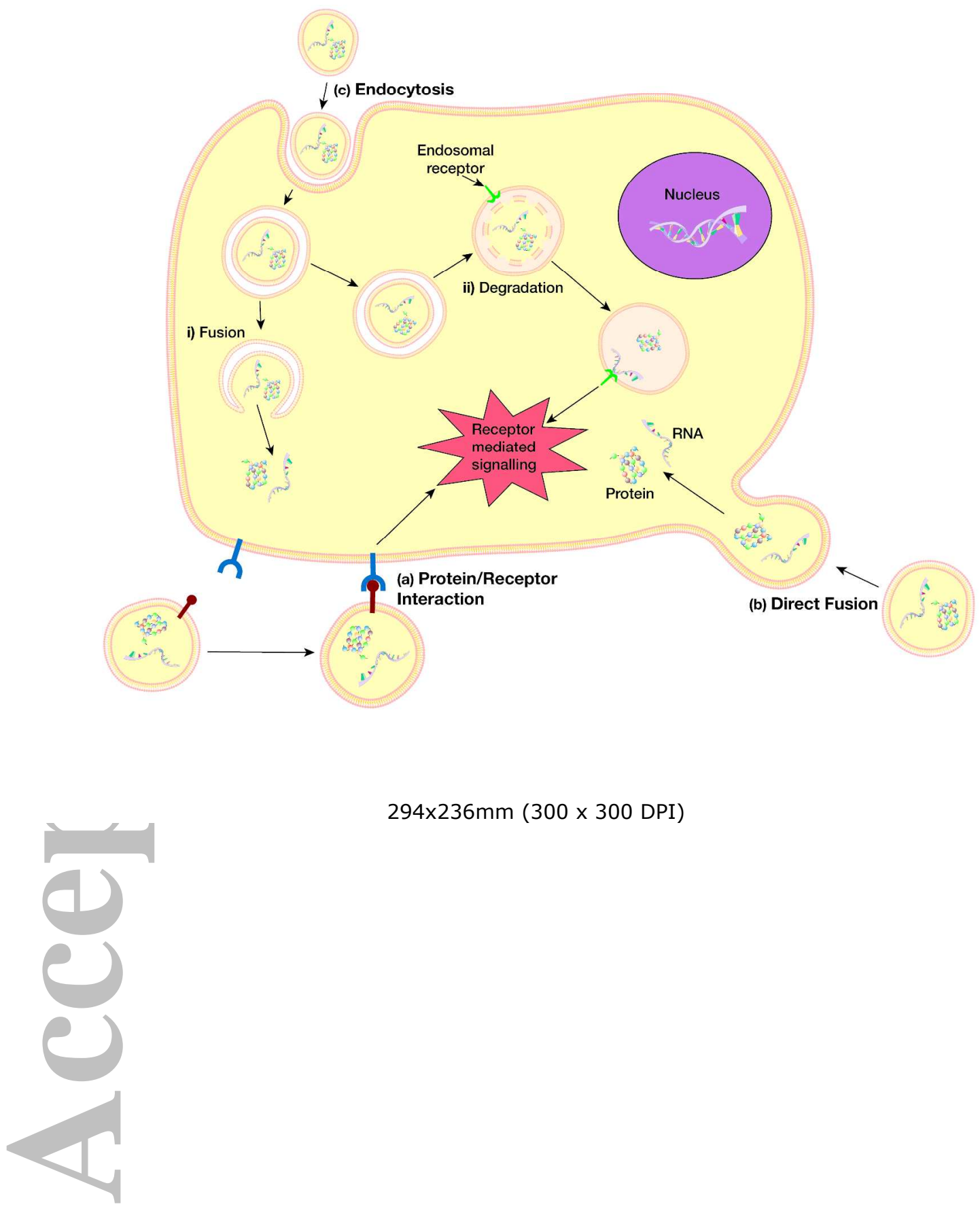

$294 \times 236 \mathrm{~mm}(300 \times 300$ DPI)

John Wiley \& Sons

This article is protected by copyright. All rights reserved. 


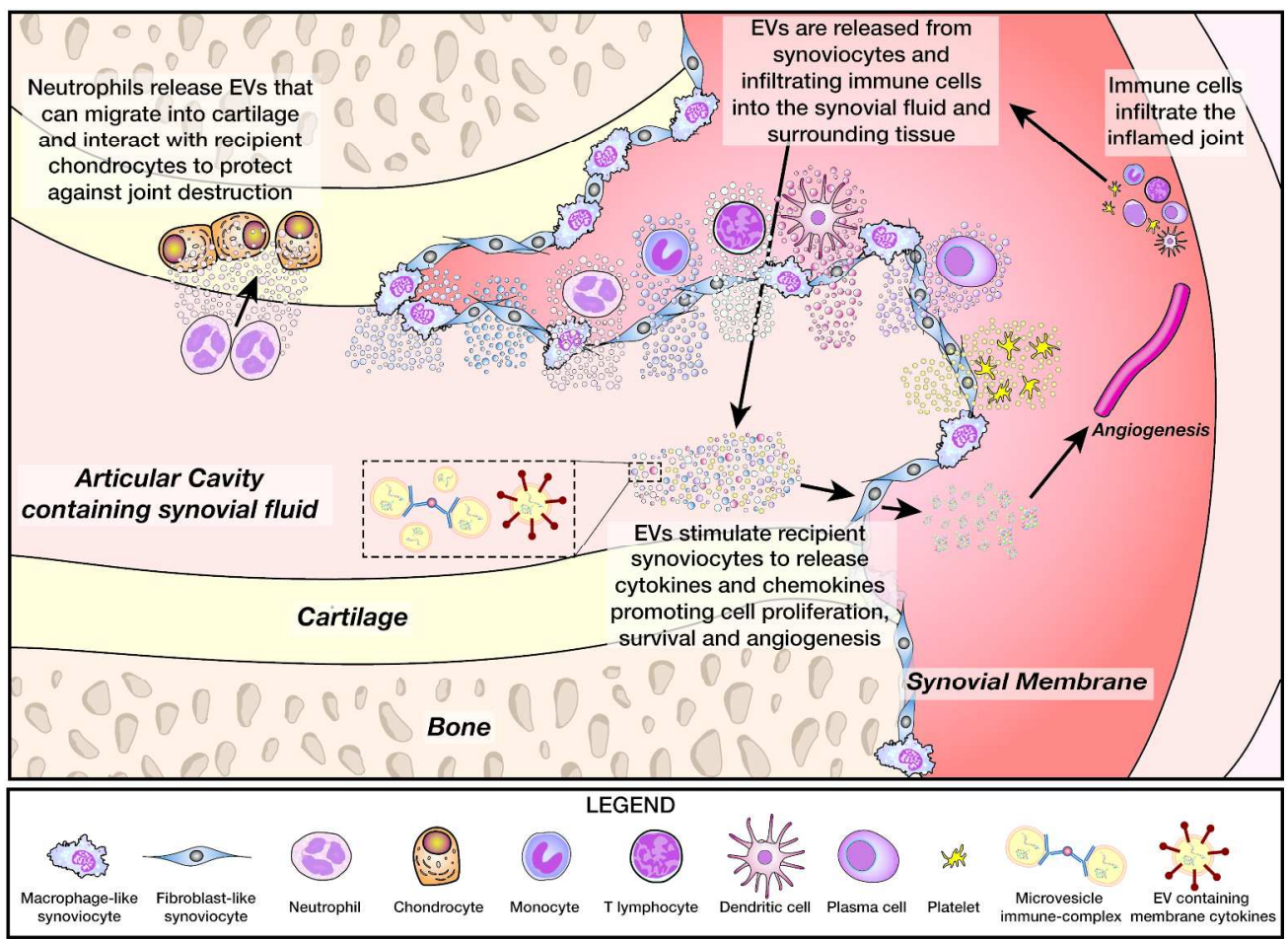

$247 \times 181 \mathrm{~mm}(300 \times 300$ DPI $)$

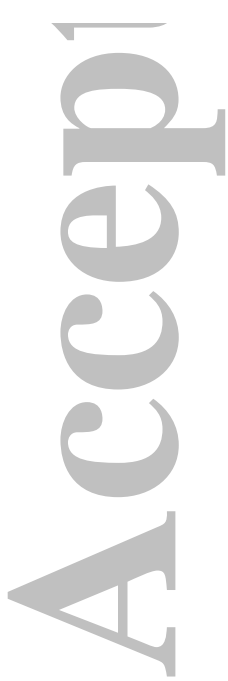


a)

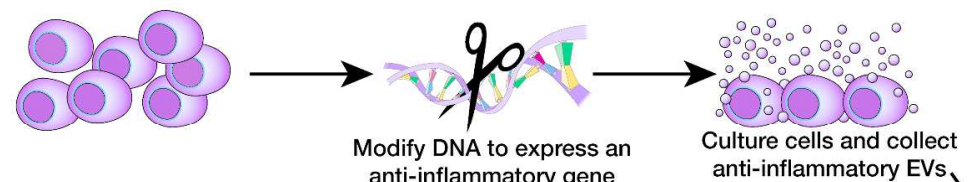
anti-inflammatory gene (e.g. Fas Ligand)

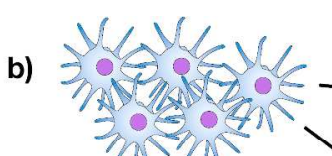

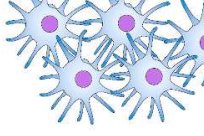

c)

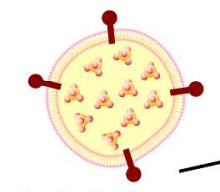

Synthetic liposomes containing membrane-bound target molecules (e.g. folate) and loaded with anti-inflammatory molecules (e.g. methotrexate)

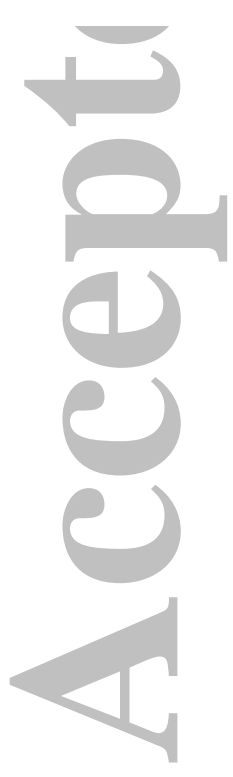

$278 \times 185 \mathrm{~mm}(300 \times 300 \mathrm{DPI})$ 


\section{University Library}

\section{- M M I E R R V A gateway to Melbourne's research publications}

Minerva Access is the Institutional Repository of The University of Melbourne

Author/s:

Foers, AD;Cheng, L;Hill, AF;Wicks, IP;Pang, KC

Title:

Extracellular Vesicles in Joint Inflammation

Date:

2017-07-01

Citation:

Foers, A. D., Cheng, L., Hill, A. F., Wicks, I. P. \& Pang, K. C. (2017). Extracellular Vesicles in Joint Inflammation. ARTHRITIS \& RHEUMATOLOGY, 69 (7), pp.1350-1362. https:// doi.org/10.1002/art.40076.

Persistent Link:

http://hdl.handle.net/11343/292997 